\title{
Genetic tools for the development of recombinant lactic acid bacteria
}

\author{
Jiapeng Wu, Yongping Xin, Jian Kong ${ }^{*}$ and Tingting Guo* (D)
}

\begin{abstract}
Lactic acid bacteria (LAB) are a phylogenetically diverse group with the ability to convert soluble carbohydrates into lactic acid. Many $L A B$ have a long history of safe use in fermented foods and are recognized as food-grade microorganisms. LAB are also natural inhabitants of the human intestinal tract and have beneficial effects on health. Considering these properties, LAB have potential applications as biotherapeutic vehicles to delivery cytokines, antigens and other medicinal molecules. In this review, we summarize the development of, and advances in, genome manipulation techniques for engineering $L A B$ and the expected future development of such genetic tools. These methods are crucial for us to maximize the value of $L A B$. We also discuss applications of the genome-editing tools in enhancing probiotic characteristics and therapeutic functionalities of $L A B$.
\end{abstract}

Keywords: Lactic acid bacteria, Food-grade microorganisms, Genome-editing tools, Probiotic characteristics, Therapeutic functionalities

\section{Background}

Lactic acid bacteria (LAB) were unknowingly used as starters in fermented dairy products for thousands of years [1]. Toward the end of the nineteenth century, Pasteur identified lactic acid fermentation of yogurt, after which Lister obtained the first pure LAB culture [2]. Since then, LAB have been studied in depth, and their physiology and genetic characteristics were gradually revealed. Nowadays, strains of LAB play indispensable roles in the dairy industry and in the manufacture of beverages, meat and vegetables, in the production of safe, healthy, tasty, and nutritious fermented foods [3]. At the same time, LAB are normal inhabitants of the human intestinal tract and the most common microbes used as probiotics $[4,5]$.

With the evolution of sequencing technologies, the human gut microbiome is being decoded. Its relationships to human health have opened up the use of

*Correspondence: kongjian@sdu.edu.cn; guotingting@sdu.edu.cn State Key Laboratory of Microbial Technology, Shandong University, Qingdao 266237, People's Republic of China next-generation probiotics as therapeutics and diagnostics. In this field, strains must be safe and survive in the intestinal tract [6]. Considering these factors, LAB may serve as ideal chassis to produce functional compounds in vivo or in vitro. Moreover, LAB can directly contact with intestinal mucosa, making them the preferred carriers of antigens and medical molecules to promote mucosal immunity [7]. A full set of technologies is required to manipulate $\mathrm{LAB}$ for therapeutic and diagnostic purposes, including but not limited to introducing DNA into LAB cells, and site-specific chromosomal mutations, deletions, stable integrations, and insertions. In the past 30 years, the genetic toolbox for $\mathrm{LAB}$ has been improved by the development of various components, such as the Cre-loxP and $\lambda$-Red or RecET systems. Encouragingly, the clustered regularly interspaced short palindromic repeats-CRISPR-associated proteins (CRISPR-Cas) system has opened a new chapter of genome editing research. In this article, we review the technologies for manipulation of LAB genomes and their use to channel LAB as microbial cell factories and delivery vehicles for the treatment of various conditions. 


\section{Uptake of foreign DNA by LAB}

Introduction of foreign DNA into LAB is an indispensable step in genetic manipulation. Natural transformation (NT) is one of the commonest pathways that mediate horizontal gene transfer in microbial species. During NT, competence for DNA transformation is induced in response to signaling peptides referred to as competence pheromones. Competent cells generally interact with double-stranded DNA (dsDNA) in the environment, but only a single strand of this DNA is translocated into the cytoplasm. Upon uptake into the cytoplasm, this single-stranded DNA (ssDNA) is rapidly bound by proteins including the recombination protein RecA and the DNA processing protein DprA, then the ssDNA can be directly integrated into the genome. NT has been adopted as a highly efficient tool for genetic manipulation of Streptococcus pneumoniae for $>60$ years. The master competence regulator ComX, responsible for DNA binding, uptake and recombination, has been identified in all streptococcal species $[8,9]$. Therefore, NT was explored for genetic manipulation of Streptococcus thermophilus [10]. This method allows transformation of S. thermophilus with classical vectors and with linear fragments that can be directly integrated into the chromosome if they are flanked by 1-kb homologous fragments corresponding to the upstream and downstream regions where the foreign DNA needs to be inserted [10]. Moreover, the use of linear fragments allows insertion of large DNA fragments (up to $15 \mathrm{~kb}$ ), which is challenging using plasmid vectors [11]. For some strains of $S$. thermophilus, the transformation rate was only $1 \%$, thus the process could be improved [12]. In addition to streptococci, Lactococcus lactis can also be endowed with the ability for NT by overproduction of the master competence regulator ComX [13]. Culture conditions and regulatory mechanisms should be further explored to achieve NT in other species of LAB.

Electroporation is the simplest artificial transformation technology. Electroporation protocols have been well developed for frequently-used host LAB species, such as Lc. lactis, Lactobacillus casei, Lb. plantarum, $L b$. brevis and $S$. thermophilus. First, cells are made competent by cultivation in medium containing hypertonic and cell wall weakening solutions, to attenuate the natural barrier to foreign DNA. Then, the competent cells are subjected to high-voltage pulses, and transient membrane pores are formed that allow the entrance of the negatively-charged DNA molecules [14, 15]. Electroporation is highly efficient. However, the electroporation protocols might not work in uncommonly-used genetic hosts such as wild-type strains isolated from the human gastrointestinal tract. Therefore, alternative natural methods, such as transduction and conjugation, are gaining renewed attention to achieve plasmid or chromosomal DNA transfer between LAB strains; the former is a phage-mediated DNA transfer method, and the latter can achieve DNA translocation between two cells that form a mating pair using two types of mobile genetic elements: conjugative plasmids and integrating conjugative elements (ICEs) [16-18].

\section{Gene knock-out and knock-in technologies in LAB}

Chromosomal disruption and integration strategies were established in LAB based on traditional non-replicative plasmids (pWV01, pG+host) and insertion sequence (IS) transposons [19-21]. To accelerate screening of recombinants, researchers introduced appropriate counterselectable markers, such as uracil-phosphoribosyltransferase (UPRT), the orotate transporter (OroP), and phenylalanyl-tRNA synthetase (PheS) [22-25]. Emerging technologies are being developed in LAB, such as dsDNA or ssDNA recombineering and CRISPR-Cas systems, which greatly simplify the procedures of gene knock-out or knock-in in LAB chromosomes and improve the efficiency of generation of target mutants.

\section{Recombineering}

Recombineering refers to homologous recombination between exogenous DNA and the bacterial genome, to achieve gene deletion, insertion, or replacement. Recombineering includes dsDNA recombineering and ssDNA recombineering [26, 27]. DsDNA recombineering is mediated by bacteriophage-encoded recombinase systems, $\lambda$-Red $\alpha \beta \gamma$ and RecET. Red $\alpha / \operatorname{RecE}$ is a $5^{\prime}$-3dsDNA exonuclease that digests exogenous dsDNA to generate 3 -ended ssDNA overhangs. $\operatorname{Red} \beta / \operatorname{Rec} \mathrm{T}$ is a single strand annealing protein that binds to the ssDNA overhangs and promotes strand exchange and strand invasion. Redy inhibits the RecBCD nuclease from attacking linear DNA [28]. Thus, when dsDNA substrates are electroporated into cells, Red $\alpha / \operatorname{RecE}$ digests the dsDNA to produce ssDNA overhangs, Red $\gamma$ inhibits the activity of the endogenous bacterial nuclease $\operatorname{RecBCD}$, and $\operatorname{Red} \beta / \operatorname{Rec} T$ binds to the ssDNA overhangs to promote the renaturation of complementary strands and mediates DNA strand annealing and exchange reactions [28].

The feasibility of $\lambda$-Red- and RecET-like systems in $\mathrm{LAB}$ was first reported when Yang et al. identified a $\lambda$-Red like recombinase system from a prophage of $L b$. plantarum WCFS1; Lp_6040, Lp_6041, and Lp_6042 were the analogs to $\operatorname{Red} \gamma, \operatorname{Red} \alpha$, and $\operatorname{Red} \beta$, respectively. Combining the Lp_6040-41-42 system with the Cre-loxP system (a site-specific recombinase system consisting of 34 bases) yielded efficient deletion of the glucosamine6-phosphate isomerase gene $(g n p)$ and replacement of the D-lactate dehydrogenase gene $(l d h D)$ with mutation 
efficiencies of $95 \%$ and $75 \%$, respectively in $L b$. plantarum WCFS1 [29]. Xin et al. explored another $\lambda$-Red like recombinase system, LCABL_13040-50-60, to mediate markerless deletion of a 167-bp galk fragment and insertion of the green fluorescent protein gene $(g f p)$ with mutation efficiency of $100 \%$ in Lb. casei BL23 (Fig. 1) [30]. Xin et al. also extended the LCABL_13040-50-60 recombination system into 12 strains of lactobacilli and one of Lactococcus, which broadened the host range of the recombinase system [30]. DsDNA recombineering can be used for deletions, insertions or replacements of large gene fragments (up to $4.7 \mathrm{~kb}$ in $\mathrm{Lb}$. plantarum) by integrating dsDNAs into the genome [29]. However, the selection of positive mutants is marker-dependent, and a scar (a loxP site) is left at the modification locus after excision of the selection marker. ssDNA recombineering neatly avoids this problem. SsDNA recombineering only requires the overexpression of $\operatorname{Red} \beta / \operatorname{Rec} T$, and ssDNA can be guided by $\operatorname{Red} \beta / \operatorname{Rec} T$ to homologous sequences on the bacterial chromosome [31]. The first successful attempt of ssDNA recombineering in LAB species was carried out in $L b$. reuteri ATCC PTA 6475. Transformation of $100 \mu \mathrm{g}$ ssDNA into $L b$. reuteri after expression of RecT from Enterococcus faecalis (E. faecalis) yielded precise mutation with efficiency $0.4-19 \%$ [31]. Because ssDNA recombineering did not use antibiotic selection markers in $L b$. reuteri, the efficiency of obtaining positive mutants was relatively low. Therefore, it is necessary to develop new screening strategies to capture positive mutants more easily.

\section{CRISPR-Cas-based systems}

CRISPR-Cas system constitute adaptive immune systems in bacteria and archaea that can actively reject the invasion of foreign genetic elements such as phages and plasmids [32]. Since 2013, genome editing using

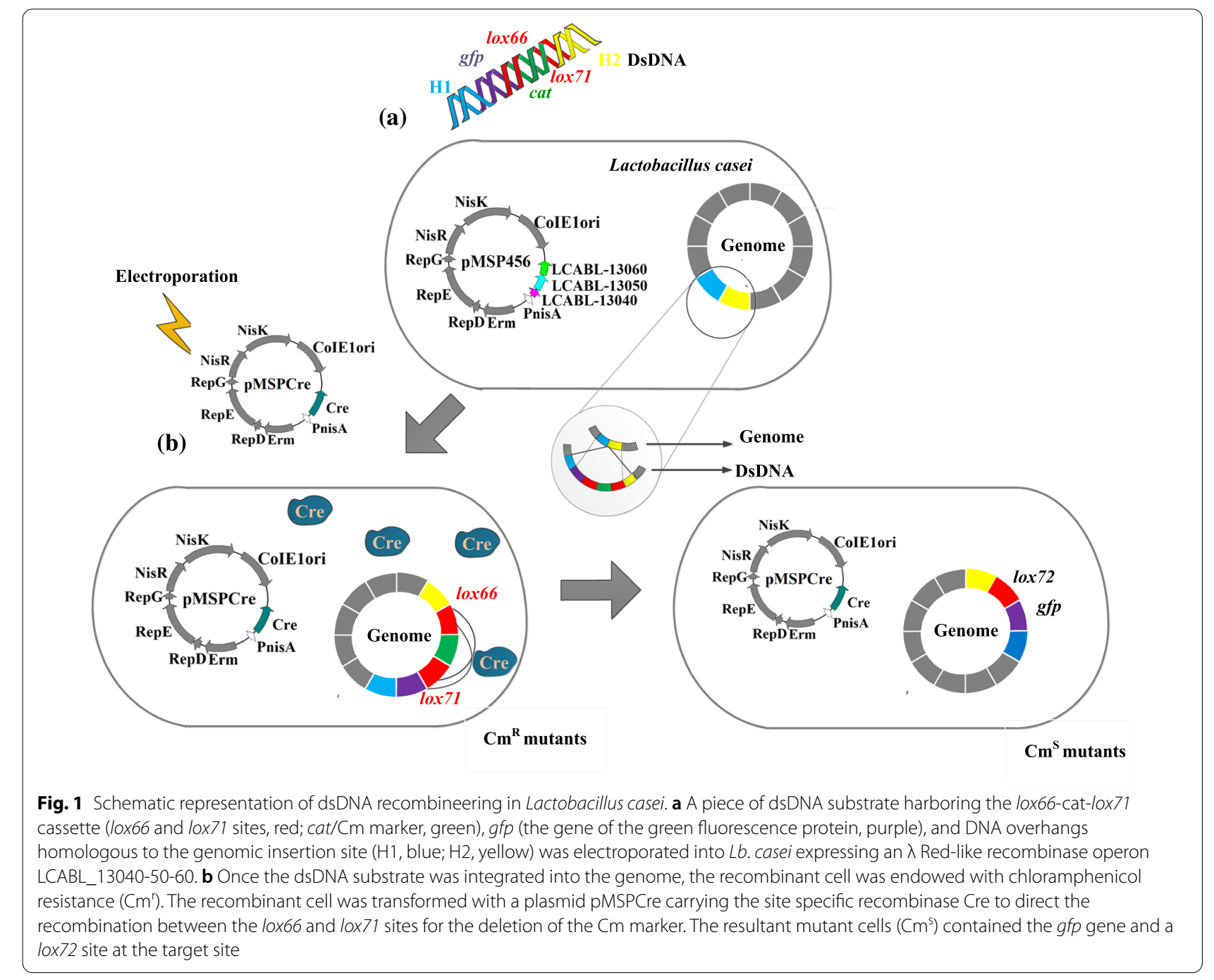


CRISPR-Cas systems has undergone explosive growth. In particular, the type II CRISPR-Cas9 system from $S$. pyogenes has been exploited as a facile and programmable platform for genome editing in a sequence-specific manner in some eukaryotes and prokaryotes. The system consists of Cas9 (an endonuclease), a trans-activating CRISPR RNA (tracrRNA) and a precursor crRNA array containing nuclease guide sequences (spacer) interspaced by identical direct repeats [33]. The precursor crRNA is processed within repeat sequences to generate mature crRNA, which further forms a duplex with the tracrRNA. The duplex interacts with Cas9, searches present DNA for a trinucleotide protospacer adjacent motif (PAM), and binds to proximal chromosomal complementary sequences (protospacer), inducing double-stranded breaks (DSBs) in the chromosome [34]. The lethal (unless repaired) DSBs stimulate the non-homologous end joining recombination (NHEJ) (existed in rare bacteria) or homologous recombination (HR) pathway to repair the DNA lesion, and thus desired mutations can be produced [34]. Moreover, CRISPR-Cas9 can be used as a counterselectable marker, as Cas9-induced DSBs in the wildtype allele allow rapid screening of expected mutants.

In 2014, a RecT-assisted CRISPR-Cas9 approach was developed to perform codon saturation mutagenesis and gene deletions in the chromosome of $L b$. reuteri ATCC PTA 6475 [35]. A similar approach was used in Lc. lactis NZ9000; seamless genomic DNA insertion or deletion (Fig. 2a, b) was efficiently accomplished within $72 \mathrm{~h}$ [36]. The CRISPR-Cas9 system was even used to modify the genome of the Lc. lactis virulent phage P2 and precise mutations were successfully achieved without the assistance of heterologous recombinases [37]. Leenay et al. used two plasmids carrying the recombineering template and CRISPR-Cas9 elements to achieve genome editing in $L b$. plantarum WJL, but this failed in Lb. plantarum NIZO2877 and $L b$. plantarum WCFS1, indicating that the genetic engineering feasibility of the method varied depending on the targeted gene(s) and strain [38]. Variants of Cas9 have also been developed, such as Cas9 nickase $\left(\mathrm{Cas}^{\mathrm{D} 10 \mathrm{~A}}\right)$, which generates chromosomal singlestrand breaks (nicks), circumventing the high lethality of DSBs induced by Cas9 [34]. A CRISPR-Cas9 ${ }^{\text {D10A }}$-based plasmid was constructed for genome engineering of $L b$. casei LC2W, which allowed enhanced green fluorescent protein (eGFP) gene insertion and putative uracil phosphoribosyltransferase (UPRT) gene deletions with efficiencies of $35 \%$ and $65 \%$, respectively [39].

In addition to introducing point mutations, deletions and insertions in targeted genes, the CRISPR system can be used to regulate gene expression through CRISPR interference (CRISPRi) with catalytically inactive variants of Cas9 (dCas9), in which the endonucleolytic activity of
Cas9 has been eliminated but the targeted binding function was still remains [40]. CRISPRi systems served as robust tools for transcriptional regulation of the essential cell cycle genes in Lb. plantarum [41, 42]. This work provided an ideal example of how to quickly screen both essential and nonessential genes by CRISPRi-mediated knockdowns. The CRISPRi system was also used to perform single gene or multiple genes silencing in Lc. lactis [41, 43]. Table 1 summarizes the current tools available for genome editing of LAB.

\section{Gene integration into the chromosome}

LAB have relatively simple metabolic pathways and can survive in the intestinal tract. Therefore, they are ideal candidates for delivery of cytokines, antigens, and other pharmaceutical molecules [44-46]. Previously, expression of the target genes using plasmids was a common strategy for producing desired metabolites, but antibiotics must be added as selective pressure to maintain the presence of plasmids in LAB. Integration of target genes or gene clusters into the chromosome of LAB is preferable, to avoid the potential product safety risks and environmental pollution associated with antibiotic use. Using dsDNA or ssDNA recombineering strategy, genes of interest can be knocked-in to the target locus in the chromosome, but both the size and copy number of inserted genes are limited. To achieve integration of large DNA fragments or gene clusters at one or several chromosomal loci, the site-specific recombination systems can be adopted. The site-specific recombinase catalyzes the recombination between the recombinase recognition sites on a circular DNA and the chromosome. Moreover, after one round of integration, an additional recognition site is generated in the chromosome, so it is possible to achieve repetitive integration of target genes into the target sites. As proof of this concept, we constructed the recombinant $L b$. casei BL23 strains in which the $g f p$ gene or the fimbrial adhesin gene $f a e G$ from Escherichia coli was repetitively integrated into the chromosome using the Cre-loxP system. GFP and FaeG were stably expressed in the recombinant strains without supplementation of the culture with antibiotics, and the protein production was comparable to that of a plasmidengineered strain (Fig. 3) [47].

In addition to the Cre-loxP system, other site-specific recombinases from $\mathrm{LAB}$ prophages have been developed as genomic integration tools. Researchers constructed an integration vector with several new genetic traits using both the integrase and attP sequences of phage ФAT3. The integration vector was capable of stably integrating the $g f p$ gene into the chromosome of lactobacilli [48]. Although the efficiencies and accuracy of site-specific recombination systems are satisfactory, their application 


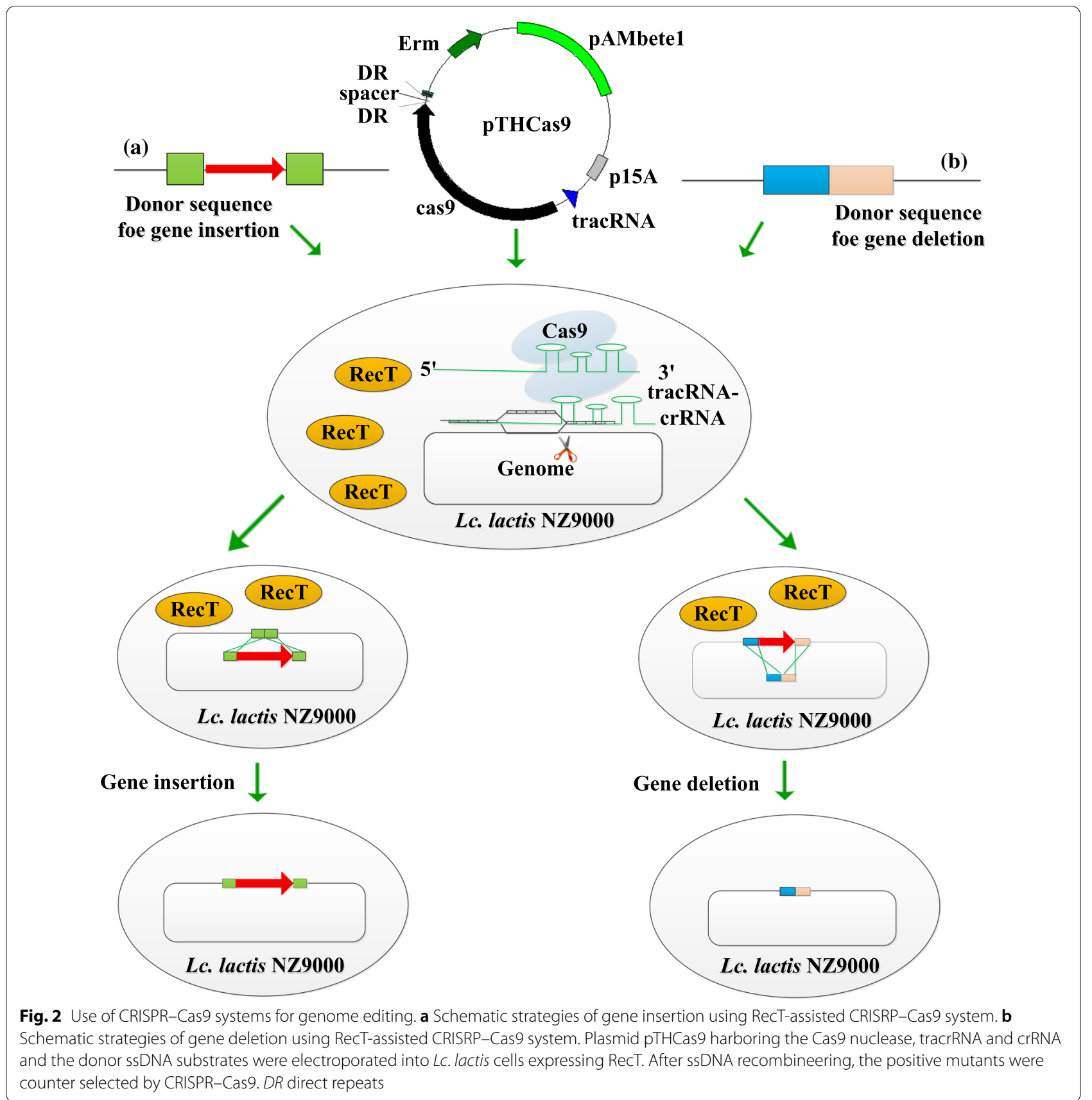

is restricted because most LAB strains lack the necessary recognition sites in the chromosome. Fortunately, insertion of the recombinase recognition sites $(\operatorname{lox} P)$ into the chromosome provided a convenient method to integrate the targeted genes, as in reports for $L b$. casei and Lc. lactis $[31,36]$.

\section{Applications of genome-editing tools in enhancing probiotic characteristics and therapeutic functionalities of LAB}

The sections above describe emerging and potential tools that allow rapid, efficient genetic engineering of LAB. They enable production of tailored probiotics with specific traits, enhancing the probiotic characteristics and therapeutic functionalities of the bacteria. 
Table 1 Current tools available for lactic acid bacteria genome editing

\begin{tabular}{|c|c|c|c|}
\hline Tools & Examples of partial applications & Characteristics & References \\
\hline Plasmids-based allelic exchange & Lc. lactis, S. thermophilus, E. faecalis & $\begin{array}{l}\text { Homologous recombination-dependent; marker } \\
\text { free; time-consuming }\end{array}$ & {$[19,20]$} \\
\hline DsDNA recombineering & Lb. plantarum, Lb. casei & $\begin{array}{l}\text { Recombinase-mediated; high efficiencies for both } \\
\text { deletion and insertion; marker-dependent }\end{array}$ & {$[29,30]$} \\
\hline SsDNA recombineering & Lb. reuteri, Lc. lactis, Lb. plantarum, Lb. gasseri & $\begin{array}{l}\text { Mutation efficiency 0.4-19\%; applicable to genomic } \\
\text { mutagenesis; marker free }\end{array}$ & {$[31]$} \\
\hline CRISPR-Cas-assisted recombineering & Lb. reuteri, Lc. Lactis & $\begin{array}{l}\text { High efficiency (up to } 100 \%) \text { for small deletions } \\
(<1.0 \mathrm{~kb} \text { in Lb. reuteri, }<100 \text { bp in Lc. lactis); marker } \\
\text { free }\end{array}$ & {$[35,36]$} \\
\hline CRISPR-Cas9D10A & Lb. casei & $\begin{array}{l}\text { Used for both gene deletion and insertion (25-65\%); } \\
\text { simplified editing procedure; marker free }\end{array}$ & {$[39]$} \\
\hline CRISPRi & Lb. plantarum, Lc. lactis & $\begin{array}{l}\text { Used to repress multiple target genes simultane- } \\
\text { ously; reversible effects; precise targeting; marker } \\
\text { free }\end{array}$ & {$[40-43]$} \\
\hline
\end{tabular}

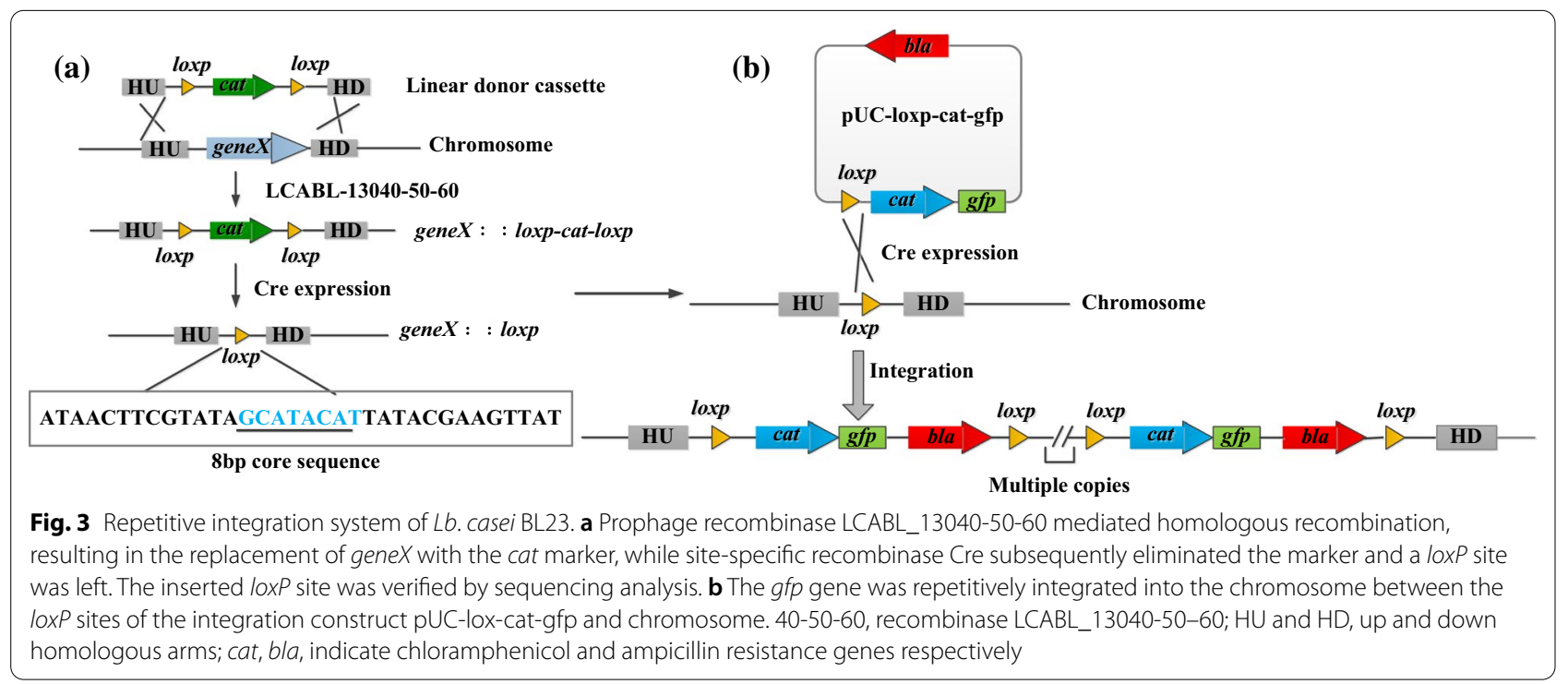

\section{Enhanced probiotic strains and starter cultures}

Bacteria must endure a variety of harsh conditions either in industrial environments or in the gastrointestinal tract, including oxidative and osmotic stress, acid and bile, pathogens, and the host immune response. These stresses pose a challenge to survival and effective colonization. Exopolysaccharides (EPS) is important for stress resistance [49]. Researchers have demonstrated that spontaneous mutations of the hypothetical membrane-anchored protein Balat_1410 and the putative tyrosine kinase EpsC altered EPS properties in Bifidobacterium animalis subsp. lactis and $L b$. johnsonii, respectively, resulting in cells that were resistant to gastrointestinal stress $[49,50]$. $S$. thermophilus cannot grow on galactose and ferments only the glucose portion of lactose; the residual galactose is excreted into the medium, which would have adverse effects on galactosemia patients. Spontaneous mutation in the galKTEM promoter of S. thermophilus produced a mutant strain with galactose-consuming ability [51]. Using the emerging genome editing technologies, such as the CRISPR-Cas systems, the introduction of single nucleotide mutations would undoubtedly faster than spontaneous mutation through consecutive cultures. Other galactose transformation pathways could also be introduced into $S$. thermophilus using genomic integration strategies [52].

\section{Engineered $L A B$ for delivery of biotherapeutics}

$\mathrm{LAB}$ are appealing as vaccine carriers as they are able to induce both mucosal and systemic immune responses, 
and are free from the risks of conventional attenuated live pathogens [7]. Steidler et al. reported the application of engineered Lc. lactis to secrete interleukin-10 (IL-10) for the treatment of inflammatory bowel disease (IBD) in colitis-induced mice [44]. In Lc. lactis, the essential thy $A$ gene (encoding thymidylate synthase) was replaced by the IL-10-encoding gene; when deprived of thymidine or thymine, the viability of the strain decreased by several orders of magnitude, essentially preventing its accumulation in the environment [53]. Lc. lactis without thyA has been evaluated in human clinical trials, and even though the trial did not satisfy expectations regarding efficacy, the bio-containment strategy was highly successful [54]. Since the use of IL-10 for IBD treatment, many other cytokines have been produced in Lc. lactis, including IL-12 and IL-6 [55, 56]. Apart from delivering cytokines, LAB have also been developed as cell factories for production and delivery of allergens. For example, $L c$. lactis CHW9 was used to produce peanut allergen Ara 2; Lc. lactis NZ9800 was used to deliver the major birch allergen Bet-v1; and $L b$. plantarum NCL21 was used to produce a major Japanese cedar pollen allergen, Cry j1, that can suppress allergen-specific immunoglobulin $\mathrm{E}$ response and nasal symptoms in a murine model of cedar pollinosis [57-59].

Recombinant $\mathrm{LAB}$ are regarded as a potential alternatives to current therapies for type I diabetes; for example, recombinant Lc. lactis NZ9000 expressed fusion protein HSP65-6P277 to improve glucose tolerance in a mouse model [60]. In the field of anticancer therapeutics, recombinant Lc. lactis NZ9000 secreting tumor metastasisinhibiting peptide Kisspeptin was used to inhibit HT-29 cell proliferation and migration through the induction of apoptosis pathways and by downregulating matrix metallopeptidase-9 expression [61]. Other cancer antigens expressed using Lc. lactis include an E7 antigen against human papilloma virus type-16 and a glycosylated tyrosinase related protein- 2 tumor antigen against melanoma (the latter has not gone to animal trials) [62, 63]. In addition to protein and peptide-based therapeutics, metabolites with medicinal applications are produced by LAB, such as $\gamma$-amino butyric acid and hyaluronic acid. The former is a non-proteinaceous amino acid with hypotensive, anticancer, antianxiety, and diuretic properties, and the latter is a carbohydrate polymer used in wound healing and to treat dermatitis $[64,65]$. The use of modified LAB as transmitters of medical molecules is very promising. Table 2 summarizes therapeutics produced by various recombinant $\mathrm{LAB}$.

\section{Conclusions and future perspectives}

Rapid progress has been made in genetic engineering of $\mathrm{LAB}$ using recombineering and CRISPR-based systems. We can obtain desired mutant strains in several days, which accelerates fundamental research and functional exploitation. CRISPR-based editing tools will be further improved in LAB, including multilocus editing and Cas9-NHEJ repair, which have been achieved in E. coli [66] and Mycobacterium tuberculosis [67, 68]. We can also learn from new achievements with CRISPR-Cas9based systems in eukaryotes. For example, new genetic information could be written into specified DNA sites using a dCas9 fused to an engineered reverse transcriptase in human cells [69]. Newly-reported insertion systems might also provide inspiration. CRISPR-associated transposases (CAST) have been explored in Vibrio cholerae and cyanobacteria. CAST were able to integrate foreign gene fragments directly into chromosomal target sites with frequencies of up to $80 \%$ without positive selection $[70,71]$. The CAST loci are approximately

Table 2 Therapeutics produced from various recombinant lactic acid bacteria

\begin{tabular}{|c|c|c|c|}
\hline Therapeutic products & Disorder/disease & Strains & References \\
\hline Interleukin-10 (IL-10) & Inflammatory bowel disease (IBD) & Lc. lactis N/S & [44] \\
\hline Interleukin-12 (IL-12) & Asthma & Lc. lactis NZ9000 & [55] \\
\hline Interleukin-6 (IL-6) & Adjuvant & Lc. lactis IL1403 & [56] \\
\hline Peanut allergen Ara2 & Hypersensitivity type I & Lc. lactis CHW9 & {$[57]$} \\
\hline Birch allergen Betv1 & Hypersensitivity type I & Lc.lactis NZ9800 & [58] \\
\hline Japanese cedar pollen allergen Cry j1 & Hypersensitivity type I & Lb. plantarum NCL21 & [59] \\
\hline HSP65-6P277 & Diabetes mellitus type I & Lc. lactis NZ9000 & {$[60]$} \\
\hline Kisspeptin & Colorectal cancer & Lc. lactis NZ9000 & [61] \\
\hline HPV-16-E7 & HPV-16 induced cancers & Lc. lactis NZ9000 & [62] \\
\hline Glycosylated tyrosinase related protein-2 & Skin cancer & Lc. lactis MG1363 & [63] \\
\hline Y-Amino butyric acid & Hypertension, anxiety & Lb. pentosus SS6 & [64] \\
\hline Hyaluronic acid & Wound healing, dermatitis & Lb. acidophilus PTCC1643 & [65] \\
\hline
\end{tabular}

N/S not specified 
$20 \mathrm{~kb}$ long and contain a Tn7-like transposase, cargo genes and V-U CRISPR system. On the basis of these characteristics, approximately $30 \%$ type $\mathrm{V}-\mathrm{U}$ putative Cas protein have been identified in 171 Lactobacillus species [72], suggesting the presence of genetic elements for the development of non-redundant and targeted genome integration systems in LAB.

In the future, the LAB genome editing platforms will be more complete. The cloning and identification of new recombinase and CRISPR systems will undoubtedly make the genetic modification of LAB faster and easier. Integration of CRISPR-based editing with synthetic biology approaches holds promise for the development of intelligent therapeutic delivery that responds to changes in the intestinal environment, such as using $\mathrm{pH}$-dependent promoters, xylose-induced expression systems, and heat shock-responsive promoters [73-75]. Although there is a long way to go before we can efficiently and reliably engineer non-model gut microorganisms, the potential benefits are considerable, and would open up new avenues for the genesis of engineered probiotic strains to improve human health with unprecedented speed, ease, and scale.

\begin{abstract}
Abbreviations
LAB: Lactic acid bacteria; NT: Natural transformation; ICEs: Integrating conjugative elements; IS: Insertion sequence; UPRT: Uracil-phosphoribosyltransferase; OroP: Orotate transporter; PheS: Phenylalanyl-tRNA synthetase; CRISPR-Cas: The clustered regularly interspaced short palindromic repeats-CRISPRassociated proteins; tracrRNA: trans-Activating CRISPR RNA; PAM: Protospacer adjacent motif; DSBs: Double-stranded breaks; NHEJ: Non-homologous end joining recombination; HR: Homologous recombination; eGFP: Enhanced green fluorescent protein; CRISPRi: CRISPR interference; EPS: Exopolysaccharides; IL-10: Interleukin-10; IBD: Inflammatory bowel disease; IL-12: Interleukin-12; IL-6: Interleukin-6; CAST: CRISPR-associated transposases.
\end{abstract}

\section{Acknowledgements}

We thank James Allen, DPhil, from Liwen Bianji, Edanz Group China (www. liwenbianji.cn/ac), for editing the English text of this manuscript, and the funding agencies for support us.

\section{Authors' contributions}

All authors listed have made a substantial, direct and intellectual contribution to the work, and approved it for publication. All authors read and approved the final manuscript.

\section{Funding}

This work was supported by grant from the National Key Research and Development Program of China (2019YFA09006700) and the National Natural Science Foundation of Shandong Province (ZR2020MC014).

\section{Availability of data and materials}

Not applicable.

\section{Declarations}

Ethics approval and consent to participate

Not applicable.

\section{Consent for publication}

Yes.

\section{Competing interests}

The author declares no competing interests.

Received: 22 March 2021 Accepted: 7 June 2021

Published online: 19 June 2021

\section{References}

1. Selhub EM, Logon AC, Bested AC. Fermented foods, microbiota, and mental health: ancient practice meets nutritional psychiatry. J Physiol Anthropol. 2014. https://doi.org/10.1186/188005-3-683-2.

2. Santer M. Joseph Lister: first use of a bacterium as a 'model organism' to illustrate the cause of infectious disease of humans. Notes Rec R Soc Lond. 2010;64:59-65.

3. Deeplina D, Arun G, Bhavdish NJ. Lactic acid bacteria in food industry. Microorg Sustain Agric Biotechnol. 2012. https://doi.org/10.1007/978-94007-2214-9_33.

4. Moal VL, Servin AL. Anti-infective activities of Lactobacillus strains in the human intestinal microbiota: from probiotics to gastrointestinal antiInfectious biotherapeutic agents. Clin Microbiol Rev. 2014;27:167-99.

5. Ashour HM, Dargahi N, Johnson J, Apostolopoulos V. Streptococcus thermophilus alters the expression of genes associated with innate and adaptive immunity in human peripheral blood mononuclear cells. PLoS ONE. 2020. https://doi.org/10.1371/journal.pone.0228531.

6. Nieuwboer MVD, Hemert SV, Claassen E, Vos WMD. Lactobacillus plantarum WCFS1 and its host interaction: a dozen years after the genome. Microb Biotechnol. 2016;9:452-65.

7. Tarahomjoo S. Development of vaccine delivery vehicles based on lactic acid bacteria. Mol Biotechnol. 2012;51:183-99.

8. Biørnstad TJ, Håvarstein LS. ClpC acts as a negative regulator of competence in Streptococcus thermophilus. Microbiology. 2011;157:1676-84.

9. Dalia AB, Dalia TN. Spatiotemporal analysis of DNA integration during natural transformation reveals a mode of nongenetic inheritance in bacteria. Cell. 2019:179:1499-511.

10. Blomqvist T, Steinmoen H, Havarstein LS. Natural genetic transformation: a novel tool for efficient genetic engineering of the dairy bacterium Streptococcus thermophilus. Appl Environ Microbiol. 2006;72:6751-6.

11 Dandoy D, Fremaux C, De Frahan MH, Horvath P, Boyaval P, Hols P, Fontaine L. The fast milk acidifying phenotype of Streptococcus thermophilus can be acquired by natural transformation of the genomic island encoding the cell-envelope proteinase Prt S. Microb Cell Fact. 2011;10:S21. https://doi.org/10.1186/1475-2859-10-S1-S21.

12. Lecomte X, Gagnaire V, Lortal S, Dary A, Genay M. Streptococcus thermophilus, an emerging and promising tool for heterologous expression: advantages and future trends. Food Microbiol. 2016. https://doi.org/10. 1016/j.fm.2015.05.003.

13. David B, Radziejwoski A, Toussaint F, Fontaine L, Hols P, et al. Natural DNA transformation is functional in Lactococcus lactis subsp. cremoris KW2. Appl Environ Microbiol. 2017. https://doi.org/10.1128/aem.01074-17.

14 O'sullivan TF, Fitzgerald GF. Electrotransformation of industrial strains of Streptococcus thermophilus. J Appl Microbiol. 1999;86:275-83.

15. Yang J, Lv C-J, Luo M-Q, Hu S, Huang J, Mei L-L, et al. Development of genetic transformation system for Lactobacillus brevis CGMCC1306. J Food Sci Biotechnol. 2016;35:584-90.

16. Belhocine K, Mandilaras V, Yeung B, Cousineau B. Conjugative transfer of the Lactococcus lactis sex factor and pRS01 plasmid to Enterococcus faecalis. FEMS Microbiol Lett. 2007;269:289-94.

17. Ammann A, Neve H, Geis A, Heller KJ. Plasmid transfer via transduction from Streptococcus thermophilus to Lactococcus lactis. J Bacteriol. 2008;190:3083-7.

18. Lampkowska J, Feld L, Monaghan A, Toomey N, Schjorring S, Bardowski J, et al. A standardized conjugation protocol to asses antibiotic resistance transfer between lactococcal species. Int J Food Microbiol. 2008;127:172-5.

19. Leenhouts KJ, Kok J, Venema G. Lactococcal plasmid pWV01 as an integration vector for lactococci. Appl Environ Microbiol. 1991;57:2562-7.

20. Maguin E, Prévost $H$, Ehrlich SD, Gruss A. Efficient insertional mutagenesis in Lactococci and other gram-positive bacteria. J Bacteriol. 1996;178:931-5. 
21. Walker DC, Klaenhammer TR. Isolation of a novel IS3 group insertion element and const ruction of an integration vector for Lactobacillus spp. J Bacteriol. 1994. https://doi.org/10.1128/jb.176.17.5330-5340. 1994.

22. Martinussen J, Hammer K. Cloning and characterization of upp, a gene encoding uracil phosphoribosyltransferase from Lactococcus lactis. J Bacteriol. 1994;176:6457-63.

23. Martinussen J, Hammer K. Powerful methods to establish chromosomal markers in Lactococcus lactis - an analysis of pyrimidine salvage pathway mutants obtained by positive selections. Microbiology. 1995;141:1883-90.

24. Solem C, Defoor E, Jensen PR, Martinussen J. Plasmid pCS1966, a new selection/counterselection tool for lactic acid bacterium strain construction based on the oroP gene, encoding an orotate transporter from Lactococcus lactis. Appl Environ Microbiol. 2008;74:4772-5.

25. Xin Y-P, Guo T-T, Mu Y-L, Kong J. Development of a counterselectable seamless mutagenesis system in lactic acid bacteria. Microb Cell Fact. 2017. https://doi.org/10.1186/s12934-017-0731-8.

26. Court DL, Sawitzke JA, Thomason LC. Genetic engineering using homologous recombination. Annu Rev Genet. 2002;36:361-88.

27. Montiel D, Kang H-S, Chang F-Y, Charlop-Powers Z, Brady SF. Yeast homologous recombination-based promoter engineering for the activation of silent natural product biosynthetic gene clusters. Proc Natl Acad Sci USA. 2015;112:8953-8.

28. Yu D, Ellis HM, Lee EC, Jenkins NA, Court DL. An efficient recombination system for chromosome engineering in Escherichia coli. Proc Natl Aca Sci USA. 2000;97:5978-83.

29. Yang P, Wang J, Qi Q-S. Prophage recombinases-mediated genome engineering in Lactobacillus plantarum. Microb Cell Fact. 2015. https:// doi.org/10.1186/s12934-015-0344-Z.

30. Xin Y-P, Guo T-T, Mu Y-L, Kong J. Identification and functional analysis of potential prophage-derived recombinases for genome editing in Lactobacillus casei. FEMS Microbiol Lett. 2017. https://doi.org/10.1093/ femsle/fnx243.

31. Van Pijkeren J-P, Britton RA. High efficiency recombineering in lactic acid bacteria. Nucleic Acids Res. 2012. https://doi.org/10.1093/nar/ gks147.

32. Horvath P, Barrangou R. CRISPR/Cas, the immune system of bacteria and archaea. Science. 2010;327:167-70.

33. Karvelis T, Gasiunas G, Miksys A, Barrangou R, Siksnys V, et al. crRNA and tracrRNA guide Cas9-mediated DNA interference in Streptococcus thermophilus. RNA Biol. 2013;10:841-51.

34. Cong L, Ran FA, Cox D, Lin SL, Barretto R, Zhang F, et al. Multiplex genome engineering using CRISPR/Cas systems. Science. 2013;339:819-23.

35. Jee-Hwan O, van Pijkeren JP. CRISPR-Cas9-assisted recombineering in Lactobacillus reuteri. Nucleic Acids Res. 2014. https://doi.org/10.1093/nar/ gku623.

36. Guo T-T, Xin Y-P, Zhang Y, Gu X-Y, Kong J. A rapid and versatile tool for genomic engineering in Lactococcus lactis. Microb Cell Fact. 2019. https:// doi.org/10.1186/s12934-019-1075-3.

37. Lemay M-L, Tremblay DM, Moineau S. Genome engineering of virulent lactococcal phages using CRISPR-Cas9. ACS Synth Biol. 2017. https://doi. org/10.1021/acssynbio.6b00388.

38. Leenay RT, Vento JM, Shah M, Martino ME, Leulire F, Beisel CL. Genome editing with CRISPR-Cas9 in Lactobacillus plantarum revealed that editing outcomes can vary across strains and between methods. Biotechnol J. 2019. https://doi.org/10.1002/biot.201700583.

39. Song X, Huang H, Xiong Z, Ai L-Z, Yang S. CRISPR-Cas 9(D10A) nickaseassisted genome editing in Lactobacillus casei. Appl Environ Microbiol. 2017:83:1259-75.

40. Qi LS, Larson MH, Gilbert LA, Doudna JA, Weissman JS, Lim WA, et al. Repurposing CRISPR as an RNA-guided platform for sequence-specific control of gene expression. Cell. 2013;152:1173-83.

41. Berlec A, Škrlec K, Kocjan J, Olenic M, Strukelj B. Single plasmid systems for inducible dual protein expression and for CRISPR-Cas9/CRISPRi gene regulation in lactic acid bacterium Lactococcus lactis. Sci Rep. 2018. https://doi.org/10.1038/s41598-018-19402-1.

42 Myrbraten IS, Wiull K, Salehian Z, Havarstein LS, Straume D, Kjos M, et al. CRISPR interference for rapid knockdown of essential cell cycle genes in Lactobacillus plantarum. mSphere. 2019. https://doi.org/10.1128/mSphe re.00007-19.
43. Xiong Z-Q, Wei Y-Y, Kong L-H, Song X, Yi H-X, Ai L-Z. Short communication: an inducible CRISPR/dCas9 gene repression system in Lactococcus lactis. J Dairy Sci. 2020;103:161-5.

44. Steidler L, Hans W, Schotte L, Neirynck S, Obermeier F, Remaut E, et al. Treatment of murine colitis by Lactococcus lactis secreting interleukin-10. Science. 2000;289:1352-5.

45. Kuczkowska K, Kleiveland CR, Minic R, Moen LF, Øverland L, Eijsink VGH, et al. Immunogenic properties of Lactobacillus plantarum producing surface-displayed Mycobacterium tuberculosis antigens. Appl Environ Microbiol. 2016;83:2782-97.

46. Jacouton E, Maravilla ET, Boucard A-S, Pouderous N, Pessoa Vilela AP, Bermúdez-Humarán L, et al. Anti-tumoral effects of recombinant Lactococcus lactis strain secreting IL-17A cytokine. Front Microbiol. 2019. https://doi. org/10.3389/fmicb.2018;03355.

47. Xin Y-P, Mu Y-L, Kong J, Guo T-T. Targeted and repetitive chromosomal integration enables high-level heterologous gene expression in Lactobacillus casei. J Dev Microbiol. 2019. https://doi.org/10.1128/aem.00013-19.

48. Lin C-F, Lo T-C, Kuo Y-C, Lin T-H. Stable integration and expression of heterologous genes in several lactobacilli using an integration vector constructed from the integrase and attP sequences of phage Phi AT3 isolated from Lactobacillus casei ATCC 393. Appl Microbiol Biotechnol. 2013;97:3499-507.

49. Horn N, Wegmann U, Dertlit E, Mulholland F, Collins SRA, Narbad A, et al. Spontaneous mutation reveals influence of exopolysaccharide on Lactobacillus johnsonii surface characteristics. PLOS ONE. 2013. https://doi.org/ 10.1371/journal.pone.0059957.

50. Hidalgo-Cantabrana C, Sánchez B, Alvarez-Martín P, López P, MartínezÁlvarez N, Margolles A, et al. A single mutation in the gene responsible for the mucoid phenotype of Bifidobacterium animalis subsp. lactis confers surface and functional characteristics. Appl Environ Microbiol. 2015;81:7960-8.

51. Sørensen Kl, Curic-Bawden M, Junge MP, Janzen T, Johansen E. Enhancing the sweetness of yoghurt through metabolic remodeling of carbohydrate metabolism in Streptococcus thermophilus and Lactobacillus delbrueckii subsp. bulgaricus. Appl Environ Microbiol. 2016;82:3683-92.

52. Moez R, Hichem C, Isabelle G, Emmanuelle M, Samir B. Production of D-tagatose, a low caloric sweetener during milk fermentation using L-arabinose isomerase. Bioresour Technol. 2011;102:3309-15.

53. Steidler L, Neirynck S, Huyghebaert N, Snoeck V, Vermeire A, Goddeeris B, Cox E, Remon JP, Remaut E. Biological containment of genetically modified Lactococcus lactis for intestinal delivery of human interleukin 10. Nat Biotechnol. 2003;21:785-9.

54. Braat H, Rottiers P, Hommes DW, Huyghebaert N, Remaut E, Remon JP, van Deventer SJ, Neirynck S, Peppelenbosch MP, Steidler L. A phase I trial with transgenic bacteria expressing interleukin-10 in Crohn's disease. Clin Gastroenterol Hepatol. 2006;4:754-9.

55. Bermudez-Humaran LG, Langella P, Cortes-Perez NG, Gruss A, TamezGuerra RS, Oliveira SC, Saucedo-Cardenas O, Montes de Oca-Luna R, Le Loir Y. Intranasal immunization with recombinant Lactococcus lactis secreting murine interleukin-12 enhances antigen-specific Th1 cytokine production. Infect Immun. 2003;71:1887-96.

56. Li HS, Piao DC, Jiang T, Bok JD, Cho CS, Lee YS, Kang SK, Choi YJ. Recombinant interleukin 6 with M cell-targeting moiety produced in Lactococcus lactis IL 1403 as a potent mucosal adjuvant for peroral immunization. Vaccine. 2015;33:1959-67.

57. Glenting J, Poulsen LK, Kato K, Madsen SM, Frokiaer H, Wendt C, Sorensen HW. Production of recombinant peanut allergen Ara h 2 using Lactococcus lactis. Microb Cell Fact. 2007;6:28

58. Daniel C, Repa A, Wild C, Pollak A, Pot B, Breiteneder H, Wiedermann $U$, Mercenier A. Modulation of allergic immune responses by mucosal application of recombinant lactic acid bacteria producing the major birch pollen allergen Betv1. Allergy. 2006;61:812-9.

59. Ohkouchi K, Kawamoto S, Tatsugawa K, Yoshikawa N, Takaoka Y, Ono K, et al. Prophylactic effect of Lactobacillus oral vaccine expressing a Japanese cedar pollen allergen. J Biosci Bioeng. 2012;113:536-41.

60. Ma Y-J, Liu J-J, Hou J, Dong Y-K, Lu Y, Wu J, et al. Oral administration of recombinant Lactococcus lactis expressing HSP65 and tandemly repeated $\mathrm{P} 277$ reduces the incidence of type I diabetes in non-obese diabetic mice. PLoS ONE. 2014. https://doi.org/10.1371/journal.pone.0105701.

61. Zhang B, Li A, Zuo F, Yu R, Zeng Z, Ma H, Chen S. Recombinant Lactococcus lactis NZ9000 secretes a bioactive kisspeptin that inhibits proliferation 
and migration of human colon carcinoma HT-29 cells. Microb Cell Fact. 2016;15:102.

62. Bermudez-Humaran LG, Cortes-Perez NG, Lefevre F, Guimaraes V, Rabot S, Alcocer-Gonzalez JM, Gratadoux JJ, Rodriguez-Padilla C, Tamez-Guerra RS, Corthier G, et al. A novel mucosal vaccine based on live lactococci expressing E7 antigen and IL-12 induces systemic and mucosal immune responses and protects mice against human papillomavirus type 16-induced tumors. J Immunol. 2005;175:7297-302.

63. Kalyanasundram J, Chia SL, Song AA, Raha AR, Young HA, Yusoff K. Surface display of glycosylated Tyrosinase related protein-2 (TRP-2) tumour antigen on Lactococcus lactis. BMC Biotechnol. 2015;15:113.

64. Zhong Y-S, Wu S, Chen F-Y, He M-X, Lin J-R. Isolation of high $\gamma$-aminobutyric acid-producing lactic acid bacteria and fermentation in mulberry leaf powders. Exp Ther Med. 2019;18:147-53.

65. Chahuki FF, Aminzadeh S, Jafarian V, Tabandeh F, Tabandeh F, Khodabandeh $\mathrm{M}$. Hyaluronic acid production enhancement via genetically modification and culture medium optimization in Lactobacillus acidophilus. Int J Biol Macromol. 2019;121:870-81.

66. Jiang Y, Chen B, Duan C-L, Sun B-B, Yang J-J, Yang S. Multigene editing in the Escherichia coli genome via the CRISPR-Cas9 system. Appl Environ Microbiol. 2015;81:2506-14.

67. Zheng X, Li S-Y, Zhao G-P, Wang J. An efficient system for deletion of large DNA fragments in Escherichia coli via introduction of both Cas9 and the non-homologous end joining system from Mycobacterium smegmatis. Biochem Biophys Res Commun. 2017. https://doi.org/10.1016/j.bbrc. 2017.02.129.

68. Yan M-Y, Li S-S, Ding X-Y, Guo X-P, Jin Q, Sun Y-C. A CRISPR-assisted nonhomologous end-Joining strategy for efficient genome editing in
Mycobacterium tuberculosis. MBio. 2020. https://doi.org/10.1128/mBio. 02364-19.

69. Anzalone AV, Randolph PB, Davis JR, Sousa AA, Luke W, David L, et al. Search-and-replace genome editing without double-strand breaks or donor DNA. Nature. 2019;576:149-57.

70. Strecker J, Ladha A, Gardner Z, Schmid-Burgk LS, Makarova KS, Zhang F, et al. RNA-guided DNA insertion with CRISPR-associated transposases. Science. 2019;365:48-53.

71. Klompe SE, Vo PLH, Halpin-Healy TS, Sternberg SH. Transposon-encoded CRISPR-Cas systems direct RNA-guided DNA integration. Nature. 2019:571:219-25.

72. Crawley AB, Henriksen ED, Stout E, Brandt K, Barrangou R. Characterizing the activity of abundant, diverse and active CRISPR-Cas systems in lactobacilli. Sci Rep. 2018. https://doi.org/10.1038/s41598-018-29746-3.

73. Asseldonk MV, Simons A, Visser H, Vos WMD, Simons G. Cloning, nucleotide sequence, and regulatory analysis of the Lactococcus lactis dnaJ gene. J Bacteriol. 1993;175:1637-44.

74. Miyoshi A, Jamet E, Commissaire J, Renault P, Philippe L, Azevedo V. A xylose-inducible expression system for Lactococcus lactis. FEMS Microbiol Lett. 2004;239:205-12.

75. Jørgensen CM, Vrang A, Madsen SM. Recombinant protein expression in Lactococcus lactis using the P170 expression system. FEMS Microbiol Lett. 2014;351:170-8.

\section{Publisher's Note}

Springer Nature remains neutral with regard to jurisdictional claims in published maps and institutional affiliations.
Ready to submit your research? Choose BMC and benefit from:

- fast, convenient online submission

- thorough peer review by experienced researchers in your field

- rapid publication on acceptance

- support for research data, including large and complex data types

- gold Open Access which fosters wider collaboration and increased citations

- maximum visibility for your research: over 100M website views per year

At BMC, research is always in progress.

Learn more biomedcentral.com/submissions 